\title{
COSTLY BLACKOUTS? MEASURING PRODUCTIVITY AND ENVIRONMENTAL EFFECTS OF ELECTRICITY SHORTAGES
}

\author{
Karen Fisher-Vanden \\ Erin T. Mansur \\ Qiong (Juliana) Wang \\ Working Paper 17741 \\ http://www.nber.org/papers/w17741
NATIONAL BUREAU OF ECONOMIC RESEARCH
1050 Massachusetts Avenue
Cambridge, MA 02138
January 2012

This research was supported by the U.S. Department of Energy's Biological and Environmental Research Program (contract \#DE-FG02-04-ER63930), and the National Science Foundation (project/grant \#450823). We wish to thank Taryn Dinkelman, Jun Ishii, Josh Linn, Nancy Rose, and seminar participants at the UC Energy Institute, Harvard University, the ASSA meetings, and NBER for helpful comments. The views expressed herein are those of the authors and do not necessarily reflect the views of the National Bureau of Economic Research.

NBER working papers are circulated for discussion and comment purposes. They have not been peerreviewed or been subject to the review by the NBER Board of Directors that accompanies official NBER publications.

(C) 2012 by Karen Fisher-Vanden, Erin T. Mansur, and Qiong (Juliana) Wang. All rights reserved. Short sections of text, not to exceed two paragraphs, may be quoted without explicit permission provided that full credit, including $(\mathcal{C}$ notice, is given to the source. 
Costly Blackouts? Measuring Productivity and Environmental Effects of Electricity Shortages

Karen Fisher-Vanden, Erin T. Mansur, and Qiong (Juliana) Wang

NBER Working Paper No. 17741

January 2012

JEL No. D24,P2,Q4

\begin{abstract}
$\underline{\text { ABSTRACT }}$
In many countries, unreliable inputs, particularly those lacking storage, can significantly limit a firm's productivity. In the case of an increasing frequency of blackouts, a firm may change factor shares in a number of ways. It may decide to self generate electricity, to purchase intermediate goods that it used to produce directly, or to improve its technical efficiency. We examine how industrial firms responded to China's severe power shortages in the early 2000s. Fast-growing demand coupled with regulated electricity prices led to blackouts that varied in degree over location and time. Our data consist of annual observations from 1999 to 2004 for approximately 32,000 energy-intensive, enterprises from all industries. We estimate the losses in productivity due to factor-neutral and factor-biased effects of electricity scarcity. Our results suggest that enterprises re-optimize among factors in response to electricity scarcity by shifting from energy (both electric and non-electric sources) into materials---a shift from "make" to "buy." These effects are strongest for firms in textiles, timber, chemicals, and metals. Contrary to the literature, we do not find evidence of an increase in self generation. Finally, we find that these productivity changes, while costly to firms, led to small reductions in carbon emissions.
\end{abstract}

\author{
Karen Fisher-Vanden \\ Pennsylvania State University \\ fishervanden@psu.edu \\ Erin T. Mansur \\ Dartmouth College \\ 6106 Rockefeller Hall \\ Hanover, NH 03755 \\ and NBER \\ erin.mansur@dartmouth.edu
}

\author{
Qiong (Juliana) Wang \\ University of Southern California \\ Environmental Studies Program \\ 3502 Trousdale Parkway, SOS B15, MC0036 \\ Los Angeles, CA 90089 \\ juliana.wang@usc.edu
}




\section{Introduction}

Resource availability and input reliability shape productivity, especially in developing countries. For some resources like water, storage devices can be used to manage unreliable services (Baisa et al. 2010). However, electricity requires that agents respond in other ways, as power is prohibitively expensive to store. A common response to sustained power supply issues is for firms to invest directly in self-generation technology. ${ }^{1}$ By crowding out other investment opportunities, blackouts reduce productivity (Reinikka and Svensson 2002). ${ }^{2}$ In contrast to the literature, this paper examines how the onset of blackouts affect productivity in an immense and rapidly-growing economy, namely China. Using enterprise-level panel data, we study how firms respond to blackouts and estimate the resulting lost productivity and environmental effects.

In the early 2000s, industrial customers in nearly every province in China experienced blackouts associated with resource scarcity (IEA 2006). ${ }^{3}$ Despite efforts to build new power plants at a rapid rate, double-digit economic growth has lead to a tight market. Furthermore, retail electricity remains under price-cap regulation with limited price response to shortages. Finally, residential and commercial electricity consumers were given priority over industrial customers. While historic in the magnitude of blackouts, this remains a major concern for China. As recently as the summer of 2011, China faced substantial power shortages. ${ }^{4}$ The severity of these blackouts dwarfs recent experiences in the United States. In 2004, China's Eastern electricity grid (an area including Shanghai) alone curtailed over 13,000,000 MWh, accounting for over two percent of annual consumption. In comparison, the rolling blackouts of California's crisis in 2000-2001 curtailed less than one 1000th that amount. ${ }^{5}$

\footnotetext{
${ }^{1}$ Alby, Detherier, and Straub (2011) find self generation increases with power outages, using firm-level data from over 80 countries. Similarly, Reinikka and Svensson (2002) find that firms invest in their own power generators when Ugandan electric power supply is unreliable and inadequate. For a review of the literature on the economic costs of blackouts, see Jyoti, Ozbafli, and Jenkins (2006).

${ }^{2}$ Recent papers show that public provision of electricity affects growth by improving labor productivity (Lipscomb, Mobarak, and Barham 2011) and by increasing rural female employment (Dinkelman 2011).

${ }^{3}$ In 2003 and 2004, most service reliability problems were due to resource issues (Chen and Jia 2006).

${ }^{4}$ Shanghai Securities News (http://english.cnstock.com/enghome/homeheadline/201105/1307904.htm accessed December 19, 2011).

${ }^{5}$ Eastern China uses 2.5 times as much electricity as California. Curtailment data are from
} 
Facing blackouts, firms may respond in several ways. First, they may decide to use self-generated electricity. Second, they may decide to outsource the production of energyintensive, intermediate goods rather than produce them directly. ${ }^{6}$ Third, they might invest in more energy-efficient technology. Any of these three responses may lead to losses in total factor productivity. In addition, if changing inputs is too costly in the short run, then firms may experience factor-neutral losses in productivity.

In China, about $80 \%$ of generation capacity is coal-fired. Therefore, power shortages are likely to reduce coal-related pollutants like sulfur dioxide, nitrogen oxides, particulate matter, and carbon dioxide. On the other hand, if firms self generate in response to shortages, this will increase diesel consumption. In particular, these small generators tend to be less efficient and more likely to be located close to urban areas. Thus, the net environmental effect of blackouts is ambiguous.

We examine these productivity and environmental effects by combining data on annual enterprise-level production and energy use with data on annual regional electricity scarcity. The data comprise an unbalanced panel of approximately 32,000 enterprises in 11 industries from 1999-2004. We estimate a cost function that incorporates a measure of electricity scarcity.

The results suggest that enterprises re-optimize in response to electricity scarcity. Primarily, they shift from energy expenditures (from both electric and non-electric, primary energy sources) into material expenditures. This is consistent with the hypothesis of outsourcing: enterprises in regions where power became scarcer shift from "make" to "buy" in obtaining intermediate goods. When estimated by industry, we find the largest effects for textiles, timber (e.g., furniture), chemicals, and metals. Further, we do not find evidence that electricity scarcity led to an increase in self generation. This is in contrast to the findings from papers that study countries with long term electricity supply issues. We conclude that blackouts were costly to firms, with the costs increasing by $9 \%$ to $22 \%$ due to factor

China's Eastern Grid Company (personal communication) and the California Public Utilities Commission (http://docs.cpuc.ca.gov/word_pdf/misc/generation+report.pdf accessed June 20, 2008), respectively.

${ }^{6}$ This relates to literatures on supply-chain management (de Kok and Graves 2003) and on second sourcing in the face of uncertainty (Dick 1992). 
biases alone. We find that these productivity changes, while costly to firms, led to small reductions in carbon emissions.

This paper proceeds as follows. In Section 2, we describe the causes of and regulatory response to the Chinese power shortage. Section 3 provides a theoretical model of how firms may respond to issues of resource adequacy. Sections 4 and 5 describe our data and empirical model, respectively. In Section 6, we report our results. We estimate the overall productivity losses and environmental effects attributable to the power shortages in Section 7 , and conclude in Section 8.

\section{Background}

Over the past few decades, investment in the Chinese power sector has experienced a boombust cycle (Fisher-Vanden 2009). Starting in 1985, the central government transferred ownership of power plants to local governments and firms. At first, this "privatization" provided suppliers with incentive to invest in new capacity. In fact, the rapid increase in new power plant construction during the 1990s lead to a glut of capacity (IEA 2006). In response, the national government imposed a building moratorium on new power plants in 1999.

However, within just a few years, the excess supply had disappeared. From 2000 to 2007, demand for electric power grew $41 \%$ (EIA 2009). Most of this growth can be attributed to the manufacturing sector, particularly in construction-related products like steel and cement. By 2006, the manufacturing sector comprised $74 \%$ of total electricity consumption (NBS 2007). In addition, while a smaller overall share, household demand has been growing about $12 \%$ per year. Power availability and reliability was further aggravated during the early 2000s by unusually hot summers and cold winters, extreme weather events such as snow storms in the mid South, and a shortage in coal supply (Lin et al. 2005, Wang 2007). As a result, 26 of the 30 Chinese provinces experienced blackouts associated with resource scarcity issues from 2002 to 2004.

The government utilized numerous mechanisms in response to these shortages. First, they instituted dynamic pricing mechanisms to smooth the load between peak and off-peak times. 
For example, Jiangsu province implemented time-of-use pricing starting in 2003. However, their effectiveness was limited by regulatory control on prices and the slow installation of real-time meters. In addition, the government reduced subsidies for some industries. In the mid 1980s, the national government began subsidizing purchased power for energy-intensive industries including aluminum, cement, steel, and other metal and non-metal manufacturing. ${ }^{7}$ Starting in 2002, rates increased for many of these industries.

The government also implemented supply-side policies to expand generation. The National Development and Reform Commission authorized the construction of new power plants and the expansion of the grid system, all backed by favorable financing packages offered through the state-owned banks. However, given the long construction cycle, the effects of these supply-side efforts were not felt immediately. As discussed in Section 5, we account for these demand and supply market-based responses. Namely, we are interested in the private industrial costs and the environmental external costs of blackouts (or more generally, regulatory-induced scarcity) rather than the overall energy costs of meeting demand growth. Presumably, these blackouts would not have occurred in a free market, whereby prices could adjust to clear the market.

However, prices did not increase to the equilibrium level. As a result, quota rationing and rolling blackouts were the most widely used mechanism to address these shortages. Planned outages and changes in production schedules were imposed to deal with the shortages. For example, in the summer of 2003, the city of Hangzhou implemented a detailed plan for rolling blackouts for industrial customers. These measures include: shifting enterprises with noncontinuous production to alternative working days (such as working for three days a week); controlling and cutting off electricity consumption at continuous production enterprises during peak hours; moving energy-intensive production to night hours; limiting power supply to key enterprises and projects; and lowering electricity consumption of commercial users. The cities of Nanjing, Shanghai, and Shantou also released similar plans in that period.

\footnotetext{
${ }^{7}$ The fertilizer and agriculture are the most heavily subsidized industries. In 1999, firms in these industries in Junan Province paid about a quarter the rate of commercial users. Even during the crisis, these industries continued to receive extremely low rates.
} 
Electricity is the dominant source of energy in the manufacturing sector, comprising more than $40 \%$ of primary energy consumption in the sector while coal is approximately $25 \%$. As a result, the manufacturing sector is extremely vulnerable to shortages in electricity supply. Depending upon a firm's ability to substitute to alternative forms of energy, this reliance on electricity may result in manufacturing firms taking the full brunt of electricity shortages.

For example, extra costs may be incurred due to the need to re-arrange production schedules. Alternatively, firms may choose to self generate which will require additional capital and diesel purchases. ${ }^{8}$ This may particularly be true for industries at the top of the rolling blackouts list. During these periods of shortages, many light industries, such as food processing or textiles, were among the first to face electricity quotas. Many of these enterprises were reported to be working only four days a week or working during off-peak hours (Natural Resources Defense Council 2003, World Bank 2005, Thompson 2005).

News reports suggested large economic costs as a result of these blackouts. Many of these reports were based on isolated case studies or surveys. For example, Zhejiang Province in the Eastern Pearl River Delta reported costs related to blackouts during 2004 to be 100 billion RMB, or $9 \%$ of gross regional product..$^{9}$ Lin et al. (2005) survey enterprises and estimate the marginal cost of an hour of outage to be 78,482 RMB or 10,000 US dollars.

\section{Theory}

We define the firm's problem as one of constrained optimization. We assume that a firm's output $y$ is generated by the production function, $y=f(k, l, m, e, n ; \theta)$, with inputs of $k$ capital, $l$ labor, $m$ material, $e$ electricity, and $n$ other energy (such as coal, oil, and natural gas). Denote the probability of a blackout $\theta$, which measures resource inadequacy or unreliability. First consider reliable electricity: i.e., $\theta=0$. For a given set of input prices,

\footnotetext{
${ }^{8}$ Rosen and Houser (2007) and IEA (2006) reported that some firms and residents installed diesel-powered self-generation in response to the scarcity. This led to a $16 \%$ increase in oil demand in 2004, accounting for $27 \%$ of the increase in world oil demand in that year.

${ }^{9}$ Chinese Business Times. (Dec. 12, 2004) http://finance.sina.com.cn/g/20041222/03001241424.shtml1. Accessed April 14, 2007.
} 
define the dual unconstrained cost function as:

$$
c_{u}=c_{u}\left(p_{k}, p_{l}, p_{m}, p_{e}, p_{n}, y\right)
$$

Shephard's Lemma implies factor demand: $x^{*}=\partial c / \partial p_{x}$, where $x=k, l, m, e, n$. Assuming a log-linear form of the production function (such as Cobb-Douglas or translog),

$$
\ln c_{u}=\ln c_{u}\left(p_{k}, p_{l}, p_{m}, p_{e}, p_{n}, y\right)
$$

we can derive an expression for the value share of factor inputs:

$$
\frac{\partial \ln c_{u}}{\partial p_{x}}=\frac{\partial c}{\partial p_{x}} \frac{p_{x}}{c}=\frac{p_{x} x^{*}}{c}, \quad x=k, l, m, e, n .
$$

Now suppose there is some probability, $\theta>0$, that electricity is unreliable. In particular, let $\widehat{e}$ be the constrained level of electricity associated with periodic blackouts: $0 \leq \widehat{e}<e^{*}$. In this constrained case, the cost function is therefore,

$$
\ln c_{c}=\ln c_{c}\left(p_{k}, p_{l}, p_{m}, p_{e}, p_{n}, y, \widehat{e}\right)
$$

where the price of electricity does not enter into the firm's marginal decisions as a result of the constraint on electricity availability (even though it enters into (4)). For a risk neutral firm, the expected log cost function for producing a given amount $\bar{y}$ is:

$$
E[\ln c(\bar{y})]=\theta \ln c_{c}(\bar{y})+(1-\theta) \ln c_{u}(\bar{y})
$$

The effect on total factor productivity (TFP) is therefore likely to be harmful. Costs increase as the constraint on electricity limits a firm's choices:

$$
\frac{\partial E[\ln c]}{\partial \theta}=\ln c_{c}(\bar{y})-\ln c_{u}(\bar{y})>0
$$

In order to determine the effect of blackouts on the expected value shares, i.e., $v s h_{x} \equiv$ $p_{x} x / c$, we compute the partial derivative of (3) with respect to $\theta$. For electricity, this is negative as the price of electricity does not enter the constrained marginal cost function:

$$
\frac{\partial v s h_{e}}{\partial \theta}=\frac{\partial^{2} \ln c}{\partial p_{e} \partial \theta}=\frac{\partial \ln c_{c}}{\partial \ln p_{e}}-\frac{\ln c_{u}}{\ln p_{e}}=-\frac{\ln c_{u}}{\ln p_{e}}<0 .
$$


For the other inputs, the sign depends on whether the input is a substitute or complement of electricity.

Firms may decide to use self-generated electricity once blackouts become more common. This would result in an increase in the firm's use of other energy sources, such as diesel oil, and greater use of capital. In this case, other energy substitutes for purchased electricity:

$$
\frac{\partial v s h_{n}}{\partial \theta}=\frac{\partial^{2} \ln c}{\partial p_{n} \partial \theta}=\frac{\partial \ln c_{c}}{\partial \ln p_{n}}-\frac{\ln c_{u}}{\ln p_{n}}>0 .
$$

Another response to blackouts may be to outsource a portion of production. Firms may decide to purchase intermediate goods rather than produce these goods from raw materials. In this case, materials would be a substitute for electricity: $\partial \ln c_{c} / \partial \ln p_{m}>\ln c_{u} / \partial \ln p_{m}$. In addition, outsourcing could result in less use of labor, capital, and other energy sources in the production of these intermediate goods. For example, a firm requiring steel as an input to production may either purchase the raw inputs (e.g., pig iron, coal and electricity) to manufacture steel on site, or the firm may decide to purchase the steel from other producers, especially if electricity is unreliable. In this case, as these other inputs are not longer needed due to outsourcing, these inputs would be complements of electricity.

Finally, firms may respond to the shortage of electricity by improving their overall energy efficiency. This would especially be the case if there were policies promoting energy efficiency at the regional level. In this case, the value share of capital would likely increase while the shares of electricity and other energy inputs would fall.

Four hypotheses emerge from the theoretical discussion above:

I. Decreased Productivity: From equation (6), we expect that blackouts will increase total costs.

II. Self Generation: One possible response to blackouts would be for the firm to self generate. This would imply a substitution away from electricity toward non-electric energy and capital.

III. Outsourcing: Another possible response to blackouts would be for the firm to outsource more and thus produce less in-house. This would imply more material use and less use of the other factors of production. 
IV. Efficiency: Lastly, blackouts may induce more energy efficiency, which would reduce both types of energy and increase capital.

\section{Data}

This paper uses three National Bureau of Statistics (NBS) data sources from 1999 to 2004. Each year, the NBS's Department of Industrial and Transportation Statistics (DITS) collects annual economic data for approximately 22,000 large and medium-size enterprises. These data include labor and capital expenditures, and other similar economic and financial variables (Fisher-Vanden and Jefferson 2008). DITS collects another data set for a subset (about 7500 each year) of these enterprises that measures annual expenditures and aggregate quantities of consumption for various energy types. We separate purchased electricity from non-electric energy consumption. We also identify self-generated power.

Note that the set of 22,000 enterprises the DITS surveys changes annually. A balanced panel would consist of only 1340 enterprises. We opt to use the much larger, full sample of approximately 45,000 observations from 32,000 enterprises, as the unbalanced nature of our panel is primarly due to the repeated cross section nature of the sampling and not due to actual entry and exit. We test the robustness of our results by using the balanced sample.

The combined data expand the set of factor inputs to capital, labor, energy, and materials (KLEM). By exploring beyond the conventional capital-labor substitution possibilities, we are able to examine the heterogeneity in factor biases from electricity shortages. The inclusion of energy in our data set allows us to explore the effects of electricity shortages on energy use and carbon dioxide emissions.

Table 1 reports our sample's share of all industrial activity over 1999-2004. Our data include only the most energy-intensive enterprises among the population of large and mediumsize enterprises (LMEs) over the years 1999-2004. It comprises just 3\% of all Chinese enterprises. However, the KLEM sample accounts for most of the industrial energy consumed (59\%), and notable shares of industrial sales (38\%), employment (31\%), and assets (20\%).

Table 2 reports quartiles of the enterprise-year observations for several variables of inter- 
est, including factor shares. We report summary statistics for input prices, which are just expenditure averages. We define the price of labor as the wage bill (plus welfare payments) divided by total employees. The price of fixed assets is total value added (less labor expenses) divided by net value fixed assets. The price of energy is calculated as total energy expenditures divided by the quantity of energy purchased in standard coal equivalent (SCE). Finally, the price of materials is calculated as the weighted average of industry prices using input-output shares from national accounts. Due to concerns over measurement error, we also examine using regional average input prices in Section 6.

For each industry, Table 3 reports factor intensities for capital, labor, materials, electricity and non-electricity energy. We classify 12 industries: mining, food, textiles, timber, petroleum products, chemicals, rubber, non-metal mineral products, metal products, machinery, electric power, and other industries. ${ }^{10}$ Not surprisingly, relative to the distribution for the total population of enterprises and for just the LMEs, the energy sample includes high proportions of enterprises in the more energy-intensive industries, including the petroleum, electric power, non-metal products, and chemical industries. In the analysis, we omit the electric power industry.

The NBS data set also classifies enterprises into seven ownership classifications, consisting of state-owned enterprises and the six other non-state classifications. In 1999, our sample is largely concentrated in the state-owned sector, i.e., $62 \%$ of total sales in our sample originated with SOEs. This SOE ownership prevalence in our sample is not surprising: a large portion of China's energy-intensive enterprises that occupy the capital-intensive sectors are state-owned. In Section 6, we examine whether ownership affects how firms responded to blackouts.

\footnotetext{
${ }^{10}$ While NBS classifies firms into 37 categories, some have insufficient observations to estimate the effects by industry.
} 


\section{Measures of Electricity Scarcity}

In 2002, China had six main regional grids - Central, East, North, Northeast, Northwest, South - each encompassing several provinces. ${ }^{11}$ Within each grid, the transmission of power is frequent and with minimal congestion. However, in the absence of long distance transmission DC lines, the transfer of electric power among grids has been difficult. As a result, in tight markets, provinces are able to provide power to other provinces located within the same regional grid through load management, but the sharing of power across grids to meet peak demand is, in most cases, impossible. Grid level performance indicators are, therefore, a meaningful way to measure the extent of power system reliability, or scarcity, within a region.

We use data on electricity shortages constructed from information obtained from various issues of the China Electricity Yearbook. These Yearbooks contain information on electricity generation $\left(G e n_{g t}^{\text {Thermal }}\right)$ and capacity $\left(\mathrm{Cap}_{g t}^{\text {Thermal }}\right)$ from thermal (primarily coal-fired) power plants. Our main measure of scarcity is the thermal utilization rate for grid $g$ at time $t$ : $S_{g t}=G e n_{g t}^{\text {Thermal }} /\left(8760 \cdot \operatorname{Cap}_{g t}^{\text {Thermal }}(1-\right.$ sor $\left.-f o r)\right)$, where sor is the scheduled outage rate and for is the forced outage rate. ${ }^{12}$ Power plants typically scheduled outages for maintenance and reliability purposes, sor. In addition, unscheduled outages occur due to equipment failure, for. Thus, the factor $(1-$ sor - for $)$ adjusts for the probability of operation. Scarcity issues are greater in the North and East grids most years, and tend to increase over time in all grids (see Figure 1).

For robustness checks, we also calculate two alternative measures of scarcity. ${ }^{13}$ Although differences do exist among the three scarcity measures, the trends of these measures are similar. As the market got tighter after 2002, all three measures point to a higher probability

\footnotetext{
${ }^{11}$ Grid systems in Xizang (Tibet) and Taiwan are not connected with China's national grid system.

${ }^{12}$ Our measures of these rates are constant over time and location. They are based on the data from the 2000 Yearbook on the scheduled and non-scheduled outage hours for thermal generators of at least $100 \mathrm{MW}$.

${ }^{13}$ The overall utilization rate, $S_{g t}^{\text {Total }}$ is $\operatorname{Gen}_{g t}^{\text {Total }} /\left[8760 \cdot \operatorname{Cap}_{g t}^{\text {Total }}(1-\right.$ sor - for $\left.)\right]$. This is not the main definition as hydro capacity can be noisy relative to thermal. The peak hourly utilization rate, $S_{g t}^{P e a k}$, is PeakLoad ${ }_{g t}^{\text {Total }} /\left[\mathrm{Cap}_{g t}^{\text {Total }}(1-f o r)\right]$, where the adjustment factor is $(1-f o r)$ excludes scheduled outages, which are unlikely to be during peak periods. This measures scarcity during the hour when the market is nearest capacity limits.
} 
of the occurrence of blackouts.

These measures were also affirmed by system operators in the Eastern Grid at interviews during field work in 2007. ${ }^{14}$ For this grid, we have additional data on the length and quantity of electricity interruptions. The correlation between the annual MWh curtailed and our main scarcity measure is $0.41 .^{15}$ Note that with annual data we are unable to examine the impact of duration, frequency, and timing of the interruptions which may affect the cost of production and the response of the enterprise.

\section{Measures of Self Generation}

In our analysis of self generation, we measure the rate variable as the percentage of energy used to generate electricity as a share of total energy consumption. We also use an indicator variable denoting any self generation. About $7 \%$ of the sample self generate. Most self generation uses diesel while conventional power plants in China use coal and hydropower. As Southern China is farther from the northern coal mines and has little hydropower, it is not surprising that this region has a greater share of enterprises that self generate. The share of enterprises that self generate do not vary systematically over time for any region.

In this analysis, we examine whether industries that are more electricity intensive are more or less likely to self generate when scarcity increases. We define an indicator variable for electricity-intensive industries that includes chemicals, non-metal products, metal products, mining, and other industries (see Table 3).

\section{Measures of Outsourcing}

In the final empirical section, we test for direct evidence of firms outsourcing. To do this, we use two data sources: the two-digit SIC code input/output matrix from the national accounts, and data on distances between each province. We then create an inverse-distance

\footnotetext{
${ }^{14}$ Interviewees suggested two additional measures for scarcity: a national, reliability index based on brownouts data in the electricity yearbooks; and the Eastern grid's data on interruptions. Neither has the regional variation and completeness of the three mentioned above.

${ }^{15}$ The correlation between annual curtailment and aggregate consumption is very high, 0.9. This may indicate that some new capacity may not have been available in the reported year.
} 
weighted average of scarcity: $S_{i t}^{\text {out }}=\sum_{j=1}^{n}\left(S_{j t} / d_{i j}\right) / \sum_{j=1}^{n}\left(1 / d_{i j}\right)$, where $n$ is the number of provinces and $d_{i j}$ is the distances between provinces $i$ and $j$.

We also create an industry outsourcing variable. First, we use our industry-specific estimates of how material shares respond to scarcity, $\beta_{m}^{k}$ (see discussion of Table 5 below). Second, for each input industry, we sum over the product of the input-output value shares $\left(V_{k j}\right)$ for each output industry and its corresponding $\beta_{m}^{k}: \Theta_{k}=\sum_{j=1}^{K} V_{k j} \beta_{m}^{j}$. Finally, we interact $S_{i t}^{\text {out }}$ and $\Theta_{k}$ to measure outsourcing. This captures when a firm is in an industry whose products are used by other firms that are both $(i)$ located in a region with scarcity issues and $(i i)$ respond to greater scarcity by increasing their materials cost shares.

\section{Empirical Model of Productivity}

We examine the productivity response to blackouts by measuring both factor-neutral and factor-biased effects. We specify a translog cost function to measure productivity changes. For firm $i$, input factor $j$, industry $k$, electricity grid $g$, and year $t$, we estimate the following equation:

$$
\begin{aligned}
\ln c_{i t}= & f\left(Q_{i t}, p_{i j t}\right)=\alpha_{0} \ln S_{g t}+\alpha_{1} \ln Q_{i t} \ln S_{g t}+\beta_{j} \ln p_{i j t} \ln S_{g t}+\delta_{j} \ln p_{i j t} \\
& +\pi_{j t} \ln p_{i j t}+\gamma_{j k} \ln p_{i j t}+\frac{1}{2} \sum_{l=1}^{J} \varphi_{j l} \ln p_{i j t} \ln p_{i l t}+\kappa \ln Q_{i t}+\frac{\lambda}{2}\left(\ln Q_{i t}\right)^{2} \\
& +\phi_{j} \ln Q_{i t} \ln p_{i j t}+\eta_{i}+\mu_{k t}+\varepsilon_{i t}
\end{aligned}
$$

where $c_{i t}$ are total production costs, $Q_{i t}$ is the gross value of industrial output (in constant prices), $p_{i j t}$ is factor price $j$ (where $j$ is fixed assets, labor, materials, electricity, or other energy), and $S_{g t}$ measures electricity scarcity.

Parameters $\alpha_{0}$ and $\alpha_{1}$ measure the factor-neutral effect of scarcity (allowing the effect to vary by $Q_{i t}$ ), while $\beta_{j}$ measure the factor-biased effects of scarcity. The null hypothesis is that production is not affected by scarcity either through factor adjustments or by making overall factor-neutral changes; i.e., $\alpha_{0}=0, \alpha_{1}=0$, and $\beta_{j}=0$. 
For each factor input, we also estimate a value share equation based on (3):

$$
v s h_{i j t}=\beta_{j} \ln S_{g t}+\delta_{j}+\pi_{j t}+\gamma_{j k}+\frac{1}{2} \sum_{l=1}^{J} \varphi_{j l} \ln p_{i l t}+\phi_{j} \ln Q_{i t}+\xi_{i t}, \quad \text { for all } j .
$$

Because equations (9) and (10) represent a system of equations in which shocks to the factor shares are likely to be correlated across the error structure of the model and to gain efficiency in the estimation, we estimate them as seemingly-unrelated regressions (SUR). ${ }^{16}$ To ensure that the coefficients exhibit the usual properties of symmetry and homogeneity of degree one in prices, we impose the constraints:

$$
\varphi_{j l}=\varphi_{l j} ; \sum_{j=1}^{J} \delta_{j}=1 ; \sum_{j=1}^{J} \beta_{j}=\sum_{j=1}^{J} \varphi_{j k}=\sum_{j=1}^{J} \pi_{j t}=\sum_{j=1}^{J} \gamma_{j k}=\sum_{j=1}^{J} \phi_{j}=0 .
$$

First we estimate the aggregate effect of scarcity on production. Then we test for heterogeneous effects by separately estimating these equations by industry.

\section{Endogeneity Issues}

Economists typically estimate these types of effects with either production or cost functions. Both approaches may have to address concerns of endogeneity. In estimating production functions, some input quantities are simultaneously determined. Instead, we use the cost function approach that requires considering the endogeneity of output.

In examining endogeneity, we began by exploring potential instruments that proxy for demand shifters. While there are not a plethora of publicly available Chinese data sets, we were able to measure provincial annual population and income. Unfortunately, the first stage was weak. Instead, we assume that firm fixed effects $\left(\eta_{i}\right)$ and industry-year fixed effects $\left(\mu_{k t}\right)$ address most of the endogeneity concerns regarding output. ${ }^{17}$

We also examine the endogeneity of scarcity. In particular, we explore whether scarcity may be caused by greater industrial activity, in particular from more electricity-intensive

\footnotetext{
${ }^{16}$ In order to have an invertible disturbance covariance matrix, we drop the value share equation of materials from the estimation. To test the robustness of results, we also drop the value share equation for capital in the estimation, and estimate the model using two alternative scarcity measures described below.

${ }^{17}$ As a robustness, we also report a model where the dependent variable is the average costs (i.e., in equation (9) we impose $\alpha_{1}=0 ; \kappa=1 ; \lambda=0 ; \phi=0$ ).
} 
firms. We use instruments that will increase scarcity by increasing the demand for electricity but not affect industrial output. The set of instruments are grid-level annual heating and cooling degree days, as well as their interactions with factor prices.

\section{Aggregate Effects of Scarcity}

Our cost function estimation allows us to compute the marginal and total effects of electricity scarcity on cost and carbon emissions. The calculation of the marginal change in cost due to scarcity is easily obtained from (9):

$$
\frac{\partial c_{i t}}{\partial S_{g t}}=\frac{\alpha_{0} c_{i t}+\alpha_{1} \ln Q_{i t} c_{i t}}{S_{g t}}+\sum_{j=1}^{J} \frac{\beta_{j} \ln p_{i j t} c_{i t}}{S_{g t}} .
$$

The first term captures the factor-neutral effects while the factor-biased effects are the remainder.

The marginal effect of scarcity on emissions $(E)$ is the product of the marginal change in quantity of fuel input due to scarcity $\partial x_{i j t} / \partial S_{g t}$ and the emissions rate $r_{j}$, where $x$ is electricity $(e)$ or other fuels $(n)$. The appendix derives the following definition of the marginal emissions:

$$
\frac{\partial E_{i j t}}{\partial S_{g t}}=r_{j}\left(\frac{\beta_{j} c_{i t}}{p_{i j t} S_{g t}}+\frac{x_{i j t}\left[\alpha_{0}+\alpha_{1} \ln Q_{i t}+\sum_{j=1}^{J} \beta_{j} \ln p_{i j t}\right]}{S_{g t}}\right)
$$

\section{Results}

Table 4 reports the main results from estimating (9) and (10). The first column reports our main specification. The coefficient on scarcity suggests that small enterprises facing greater possibilities for electricity shortages saw a significantly negative neutral effect on cost. While surprising, these cost savings dissipate with enterprise size $\left(Q_{i t}\right)$ and are insignificant for the average enterprise. Therefore, our first hypothesis that scarcity will lead to a negative effect on an enterprise's productivity as a result of the constraint on electricity availability does not hold on average. 
However, our results do suggest that scarcity has an effect on how enterprises produce; namely, scarcity leads to significant substitutions among the five factor inputs. Increased scarcity leads to a reduction in the use of electricity and other forms of energy and an increase in the use of materials. For a one standard deviation increase in scarcity, the cost share of materials increases by about one percent while that of electricity and other energy each decrease by about half that amount. The effects on labor and capital are small.

This materials-using effect of scarcity suggests that enterprises are choosing to outsource production rather than to produce in-house, consistent with our third hypothesis. We do not, however, find evidence to support our hypothesis that electricity blackouts will lead to greater self generation. We observe neither an increase in capital use, nor a substitution toward other types of energy (in particular diesel oil) that would be consistent with self generation. To the contrary, we see a significant reduction in non-electric energy. At first, this effect on energy overall seems consistent with the hypothesis that blackouts lead to energy efficiency improvements. However, we do not see an increase in capital. Hence, outsourcing appears the only hypothesis for which we find evidence.

The second column of Table 4 shows the results from our instrumental variables estimation. We find in the first stage, the set of instruments to be strong predictors of scarcity. ${ }^{18}$ The second stage of the IV regression is reported in Table 4 and shows that the IV results are similar in sign to those in column one. However, the magnitude of the effects on materials, electricity and other energy are about twice as large.

Columns three and four restrict the main model. The third column imposes a constant TFP effect for firms of all sizes. Here, a significantly negative factor-neutral effect suggests that firms may have been pushed to reduce costs during times of scarcity. Finally, the last column assumes constant returns to scale by imposing the constraints described in footnote 17. This is akin to modeling average costs as a function of scarcity. Columns 3 and 4 show similar results to our main findings.

\footnotetext{
${ }^{18} \mathrm{~A}$ Wald test on the instruments' joint significance for the $\ln$ (scarcity) regression, for instance, returns an F-statistic of 882 (p-value < 0.001).
} 


\section{Robustness}

Table 5 reports our results when we estimate (9) and (10) separately for each industry. We find large responses in electricity shares for mining, textiles, timber, and metals. Timber includes paper, pulp, and furniture. Interestingly, the industrial category "other" shows an increase in electricity, but no other significant changes in inputs making the result hard to interpret. Outsourcing was large in a several sectors: textiles, timber, chemicals, nonmetals, and metals. There were large decreases in other energy shares for mining, timber, chemicals, and nonmetals. The one industry that reported using more energy was petroleum, which may have had greater energy resources available. Most industries saw small or no changes in capital and labor shares, with mining's capital share being the exception.

Revisiting the four hypotheses from the theory section, we find evidence of outsourcing in several industries. None of the industries had results consistent with self generation. Factor-neutral effects were costly for petroleum. Small timber, rubber, and metal enterprises display negative factor-neutral effects, which is consistent with saving costs relative to the industry average. Finally, mining and nonmetal industries results are consistent with improved efficiency.

We perform several other robustness checks. In estimating the model by region, given the variation in our scarcity measure, we cannot include time fixed effects for each industry. We find that most regions had significant changes in input shares. The northeast and east experienced large drops in other energy shares. Electricity shares dropped in nearly all regions. Conversely, material shares increased throughout the country except in the southwest.

We also test whether ownership mattered. In particular, we separately estimate the model for state-owned enterprises. Here we find a significant increase in capital shares (with a coefficient of 0.064 and standard error of (0.011)). Labor shares, factor-neutral TFP, and firm size effects were small and insignificant. We find qualitatively similar effects for materials (0.033 (0.015)), electricity (-0.058 (0.009)), and non-electric energy (-0.034 (0.011)). These results are consistent with outsourcing and with technical efficiency. We test the robustness 
our results to several additional assumptions. ${ }^{19}$

\section{Self Generation}

As discussed above, our cost function results do not support the hypothesis that enterprises chose to self generate in reaction to electricity shortages. We explore this further by using a linear probability model of adoption decisions, where the dependent variable indicates self generation. Using enterprise fixed effects, we find that scarcity and scarcity interacted with an indicator of electricity-intensive industries are not significant predictors of self generation $(-0.045(0.046)$ and $-1.453(1.129))$.

If we exclude enterprise fixed effects, we can estimate a random effects probit model. Here, more electricity-intensive industries do self generate in regions with greater scarcity. The direct effect of scarcity is $-2.28(0.40)$ and the interaction term is 12.10 (4.63). Namely, when we estimate a model using cross sectional variation, we do find a "long run" effect. However, when we look only at responses over time within an enterprise, we do not see a "short run" effect. Finally, we examine the intensive usage of generation technology. We find that the fraction of electricity that is self generated is not affected by the degree of scarcity on the grid. This is the case both with a linear fixed effects model as well as a random effects Tobit model.

Note that these effects are identified off of just a few years of data, right at the time of the crisis. Installing new capital-intensive equipment might require more time to install. Similarly, firms may have been waiting to determine whether or not these blackouts would become persistent: there was option value in waiting. Finally, while there were reports of firms and residents installing self generation (Rosen and Houser 2007, IEA 2006), our sample focuses on just the largest energy users. For these firms, the costs of self supplying may have been extremely large.

\footnotetext{
${ }^{19}$ The results are robust to dropping the capital equation instead of the materials equation. Results are also robust to the two alternative measures of scarcity. We also find our results to be robust to using province-year average input prices to address the concern that firm-level input prices may be endogenous. Finally, the results are robust to just using a balanced panel of enterprises.
} 


\section{Outsourcing}

Finally, we test for direct evidence of outsourcing by estimating whether a firm's production increases when firms it sells to are threatened by scarcity. We regress a firm's output (measured in constant-dollar gross value of industrial output) on firm fixed effects and industryyear fixed effects. We also include three variables of interest: $S_{g t}, S_{i t}^{\text {out }}$ and $S_{i t}^{\text {out }} \Theta_{k}$. Standard errors are clustered by firm.

The first variable, $S_{g t}$, shows that firms reduce output when scarcity increases: -1.33 (0.64). The second variable, $S_{i t}^{\text {out }}$, suggests (though is insignificant) that firms produce more when neighboring regions have greater scarcity concerns: $3.18(2.34) .{ }^{20}$ The last variable implies that firms outsource intermediate goods: 34.00 (18.14). This effect is weakly significant $(\mathrm{p}=0.06)$ when all three effects are jointly estimated. However, when just accounting for $S_{g t}$ and $S_{i t}^{\text {out }} \Theta_{k}$, only the outsourcing effect is significant at the five percent level: 37.50 (17.76).

\section{The Private and External Costs of Shortages}

Table 6 aggregates overall effects of scarcity on production costs and carbon emissions. We calculate the marginal and total effects of changes in scarcity from 1999 to 2004 on cost and emissions. In particular, the totals are the sum of the marginal effects for each enterprise and year observation multiplied by the change in scarcity from 1999 for that observation.

Panel A provides marginal and total cost figures calculated using sample averages and at the enterprise-level. The sample average results suggest that electricity scarcities over the period 2000-2004 lead to a slight, though insignificant, increase in total costs. The costly factor-biased effects (about 9\%) exceeded the apparent cost savings from the neutral effects (about 7\%). Notably, materials costs increased substantially, with these cost increases accounting for $10 \%$ of the total costs incurred by firms in our sample from 2000 to 2010, as enterprises shifted to outsourcing the production of intermediate products. The enterpriselevel calculations suggest that the factor-neutral effects were much smaller and that, overall,

\footnotetext{
${ }^{20}$ Note that when just the first two variables are included, $S_{i t}^{\text {out }}$ is weakly significant: $3.94(2.27)$.
} 
costs increased by $20 \%$.

Panel B of Table 6 shows the effect of scarcity on emissions. The sample average effects find no significant changes in emissions. However, the enterprise-level calculations suggest that scarcities reduced emissions $11 \%$ due to non-electricity consumption. This discrepancy between the average calculation and enterprise-level calculation suggests heterogeneous effects in responding to scarcity. Note that these environmental effects are only for the decreases in electricity and other energy consumption and do not factor in the additional emissions due to outsourcing.

\section{Conclusion}

This paper examines how enterprises in China responded to a power shortage during the early 2000s. We find that enterprises in regions with greater shortages decrease factor shares of electricity and increase shares of materials. We do not find evidence of an increase of self supply. In fact, we find an overall decrease in other non-electricity energy sources, suggesting that these primary energy sources are complementary inputs in producing the intermediate products that have been outsourced. We also find that enterprises facing higher levels of scarcity became more capital intensive. This, coupled with the decrease in energy use, suggests enterprises may have improved their energy efficiency.

The overall effect of blackouts, which we proxy for with a measure of scarcity, was to increase production costs. From 1999 to 2004, enterprises' costs rose by 2-20\%, primarily due to factor substitution biases. The reduction in demand for electricity and other energy sources, which are primarily coal, resulted in a decrease in emissions of up to $11 \%$ from these facilities. However, the net effect on the environment is ambiguous as outsourcing likely increases emissions from other facilities. 


\section{References}

[1] Alby, Philippe, Jean-Jacques Detherier, and Stéphane Straub. 2011. "Let There be Light! Firms Operating under Electricity Constraints in Developing Countries," Toulouse School of Economics Working Paper 11-255.

[2] Baisa, Brian, Lucas Davis, Stephen Salant, and William Wilcox. 2010. "The Welfare Costs of Unreliable Water Service," Journal of Development Economics, 92(1), 1-12.

[3] Chen, Lijuan, and Lixiong Jia. 2006. "Reliability of Nationwide Transmission and Substation Facilities and Urban Consumer's Power Supply in 2005," Electricity, 3: 45-51.

[4] de Kok, A.G. and S.C. Graves, eds. 2003. Handbook in Operations Research and Management Science: Supply Chain Management: Design, Coordination and Operation, Volume 11, Elsevier, Amsterdam.

[5] Dick, Andrew. 1992. "An Efficiency Explanation for Why Firms Second Source," Economic Inquiry, 30(2): 332-354.

[6] Dinkelman, Taryn. 2011. "The Effects of Rural Electrification on Employment: New Evidence from South Africa," American Economic Review, 101(7): 3078-3108.

[7] Energy Information Administration (EIA). 2009. International Energy Outlook, 2009. U.S. Department of Energy, Washington, DC.

[8] Fisher-Vanden, Karen. 2009. "Energy in China: Past Trends and Future Directions," International Review of Environmental and Resource Economics, 3(3): 217-244.

[9] Fisher-Vanden, Karen, and Gary Jefferson. 2008. "Technology Diversity and Development: Evidence from China's Industrial Enterprises," Journal of Comparative Economics, 36(4): 658-672.

[10] International Energy Agency (IEA). 2006. "China's Power Sector Reforms: Where to Next?" Paris: OECD.

[11] _ _ 2007. "World Energy Outlook, 2007: China and India Insights," Paris: OECD.

[12] Jyoti, Roop, Aygul Ozbafli, and Glenn Jenkins. 2006. "The Opportunity Cost of Electricity Outages and Privatization of Substations in Nepal," Queen's University, Department of Economics, Working Paper \#1066, 24 pp.

[13] Lin, B., B. Dong, and X. Li. 2005. "An Econometric Analysis on the Power Shortages and Outages." Manuscript, Department of Economics, University of International Business and Economics, Beijing, China. 
[14] Lipscomb, Molly, Ahmed Mushfiq Mobarak, and Tania Barham. 2011. "Development Effects of Electrification: Evidence from the Geologic Placement of Hydropower Plants in Brazil," mimeo.

[15] Natural Resources Defense Council. 2003. "Demand Side Management in China: Benefits, Barriers, and Policy Recommendations." www.nrdc.org/air/energy/chinadocs/dsm.pdf. Accessed April 02, 2007.

[16] National Bureau of Statistics (NBS). 2007. "China Statistical Yearbook, 2007," Bejing, PR China.

[17] Reinikka, Ritva and Jakob Svensson. 2002. "Coping with Poor Public Capital," Journal of Development Economics, 69: 51-69.

[18] Rosen, D.H., and T. Houser. 2007. "China Energy: A Guide for the Perplexed," Peterson Institute for International Economics, Washington, DC.

[19] Thompson, E. 2005. "Power Shortages in China: Why?" China: An International Journal, 3(1): 155 - 171. http://muse.jhu.edu/journals/china/v003/3.1thomson.pdf. Accessed on April 13, 2007.

[20] Wang, Juliana Qiong. 2007. "Background Paper: The Power Sectors in China - Development, Reform, and Shortages." manuscript, Yale University.

[21] World Bank. 2005. "Demand-Side Management in China's Restructured Power Industry: How Regulation and Policy Can Deliver Demand-Side Management Benefits to a Growing Economy and a Changing Power System." Energy Sector Management Assistance Program. 


\section{Appendix}

The marginal emissions of scarcity are:

$$
\frac{\partial E_{i j t}}{\partial S_{g t}}=r_{j} \frac{\partial x_{i j t}}{\partial S_{g t}}
$$

The component, $\partial x_{i j t} / \partial S_{g t}$, can be derived from (10) and (12). From the value share equation (10), $\beta_{j}$ represents the effect of scarcity on the value share of the input $j$ :

$$
\begin{aligned}
\beta_{j} & =\frac{\partial v s h_{i j t}}{\partial \ln S_{g t}}=\frac{\partial\left(x_{i j t} p_{i j t} / c_{i t}\right)}{\partial \ln S_{g t}}=p_{i j t} \frac{\partial\left(x_{i j t} / c_{i t}\right)}{\partial \ln S_{g t}} \\
& =\frac{p_{i j t}}{\left(1 / S_{g t}\right)} \frac{\partial\left(x_{i j t} / c_{i t}\right)}{\partial S_{g t}}=\frac{p_{i j t} S_{g t}}{c_{i t}^{2}}\left(c_{i t} \frac{\partial x_{i j t}}{\partial S_{g t}}-x_{i j t} \frac{\partial c_{i t}}{\partial S_{g t}}\right) \\
& =\frac{p_{i j t} S_{g t}}{c_{i t}}\left(\frac{\partial x_{i j t}}{\partial S_{g t}}-\frac{x_{i j t} S_{g t}}{S_{g t} c_{i t}} \frac{\partial c_{i t}}{\partial S_{g t}}\right)=\frac{p_{i j t} S_{g t}}{c_{i t}}\left(\frac{\partial x_{i j t}}{\partial S_{g t}}-\frac{x_{i j t}}{S_{g t}} \frac{\partial \ln c_{i t}}{\partial \ln S_{g t}}\right)
\end{aligned}
$$

Plugging in (12) into equation (A.2), we get:

$$
\beta_{j}=\frac{p_{i j t} S_{g t}}{c_{i t}}\left(\frac{\partial x_{i j t}}{\partial S_{g t}}-\frac{x_{i j t}\left[\alpha_{0}+\alpha_{1} \ln Q_{i t}+\sum_{j=1}^{J} \beta_{j} \ln p_{i j t}\right]}{S_{g t}}\right)
$$

Rearranging, we obtain an expression for $\partial x_{i j t} / \partial S_{g t}$ in terms of parameters and other known measures such as the quantity of each factor. Multiplying this by the emissions rate yields the marginal emissions of scarcity reported in equation (13), which converts energy quantities to carbon emissions based on the carbon content of the specific energy type $j$. 


\section{Tables and Figures}

Table 1: Sample Shares in Sales, Employment, Energy Consumption, and Enterprises

\begin{tabular}{lccc}
\multicolumn{1}{c}{ Measure } & $\begin{array}{c}\text { Size of } \\
\text { All Chinese } \\
\text { Industrial Sectors }\end{array}$ & $\begin{array}{c}\text { Share of the } \\
\text { Industry that } \\
\text { are LMEs }\end{array}$ & $\begin{array}{c}\text { Share of the } \\
\text { Industry in the } \\
\text { KLEM sample }\end{array}$ \\
\hline Sales (100 million yuan) & 114,701 & $64 \%$ & $38 \%$ \\
Employment (10,000 persons) & 5,695 & $52 \%$ & $31 \%$ \\
$\begin{array}{l}\text { Assets (100 million yuan) } \\
\begin{array}{c}\text { Energy consumption (10,000 } \\
\text { tons of standard coal (SCE)) }\end{array}\end{array}$ & 148,144 & $72 \%$ & $20 \%$ \\
$\begin{array}{c}\text { Number of Enterprises } \\
\text { Number }\end{array}$ & 182,236 & $70 \%{ }^{3}$ & $59 \%$ \\
\hline
\end{tabular}

Notes: For a given row, percentages are of the annual average of total industry activity over our sample period, 1999 to 2004. LMEs are large and medium-size enterprises. KLEM sample is facilities for which we know capital, labor, energy, and materials. Assets are original value of fixed assets.

${ }^{1}$ Source: China Statistical Yearbook, 2000 (NBS, 2000). Industrial state-owned and non-state-owned with annual sales over 5 million yuan.

${ }^{2}$ Source: China Statistical Yearbook, 2000 (NBS, 2000). Industrial state-owned and non-stateowned with annual sales over 30 million yuan, employment over 300 persons, and assets over 40 million yuan.

${ }^{3}$ Due to lack of time series energy data for LME's, these values only represent 1999 values, not an average over the period 1999-2004. 
Table 2: Summary Statistics

\begin{tabular}{|c|c|c|c|c|c|}
\hline Variables & Description & $\mathrm{N}$ & $25^{\text {th }}$ & $50^{\text {th }}$ & $75^{\text {th }}$ \\
\hline sales cost & sales cost ( ¥million) & 45,056 & 59 & 121 & 294 \\
\hline output & gross value of industrial output in constant prices ( $¥$ million) & 45,056 & 59 & 130 & 316 \\
\hline vshK & value share of capital (\%) & 45,056 & $10 \%$ & $16 \%$ & $24 \%$ \\
\hline vshL & value share of labor (\%) & 45,056 & $4 \%$ & $6 \%$ & $10 \%$ \\
\hline vshM & value share of materials (\%) & 45,056 & $51 \%$ & $63 \%$ & $73 \%$ \\
\hline vshElect & value share of electricity (\%) & 45,056 & $1 \%$ & $3 \%$ & $8 \%$ \\
\hline vshNelect & value share of non-electric energy (\%) & 45,056 & $1 \%$ & $2 \%$ & $9 \%$ \\
\hline $\mathrm{pK}$ & price of capital & 45,056 & 0.18 & 0.38 & 0.83 \\
\hline $\mathrm{pL}$ & price of labor ( $¥ 1000 /$ person) & 45,056 & 8.1 & 11.9 & 17.4 \\
\hline $\mathrm{pM}$ & price of materials & 45,056 & 88.1 & 91.1 & 94.5 \\
\hline pElect & price of electricity ( $¥ 1000 /$ mwh) & 45,056 & 4.3 & 5.3 & 6.5 \\
\hline pNelect & price of non-electric energy ( $¥ 1000 /$ sce) & 45,056 & 0.36 & 0.63 & 1.6 \\
\hline scarcity & annual fossil generation over capacity (by grid, year) & 36 & 0.53 & 0.59 & 0.61 \\
\hline
\end{tabular}


Table 3: Average Value Shares by Industry for 1999

\begin{tabular}{|c|c|c|c|c|c|c|}
\hline Variables & 2-digit SIC & Capital & Labor & Elect & Non-Elect & Materials \\
\hline Mining & $06-10,12$ & $10 \%$ & $24 \%$ & $10 \%$ & $9 \%$ & $47 \%$ \\
\hline Food and Beverage & $13-16$ & $18 \%$ & $7 \%$ & $3 \%$ & $5 \%$ & $67 \%$ \\
\hline $\begin{array}{l}\text { Textile, Apparel, and } \\
\text { Leather Products }\end{array}$ & $17-19$ & $10 \%$ & $11 \%$ & $9 \%$ & $4 \%$ & $66 \%$ \\
\hline $\begin{array}{l}\text { Timber, Furniture, and } \\
\text { Paper Products }\end{array}$ & $20-24$ & $12 \%$ & $9 \%$ & $10 \%$ & $8 \%$ & $61 \%$ \\
\hline $\begin{array}{l}\text { Petroleum Processing and } \\
\text { Coking }\end{array}$ & 25 & $9 \%$ & $4 \%$ & $2 \%$ & $40 \%$ & $44 \%$ \\
\hline Chemicals & $26-28$ & $10 \%$ & $7 \%$ & $13 \%$ & $13 \%$ & $57 \%$ \\
\hline $\begin{array}{l}\text { Rubber and Plastic } \\
\text { Products }\end{array}$ & $29-30$ & $11 \%$ & $8 \%$ & $7 \%$ & $5 \%$ & $69 \%$ \\
\hline Non-Metal Products & 31 & $11 \%$ & $9 \%$ & $13 \%$ & $14 \%$ & $53 \%$ \\
\hline $\begin{array}{l}\text { Metal Processing and } \\
\text { Products }\end{array}$ & $32-34$ & $7 \%$ & $8 \%$ & $10 \%$ & $11 \%$ & $64 \%$ \\
\hline $\begin{array}{l}\text { Machinery, Equipment, } \\
\text { and Instruments }\end{array}$ & $35-37,39-42$ & $2 \%$ & $14 \%$ & $6 \%$ & $4 \%$ & $74 \%$ \\
\hline Electric Power & 44 & $22 \%$ & $7 \%$ & $3 \%$ & $28 \%$ & $40 \%$ \\
\hline Other Industry & $43,45,46$ & $19 \%$ & $13 \%$ & $13 \%$ & $10 \%$ & $45 \%$ \\
\hline
\end{tabular}


Table 4: The Cost of Electricity Reliability

\begin{tabular}{|c|c|c|c|c|}
\hline Variable & SUR & IV-SUR & No Interaction & Impose CRS \\
\hline $\ln$ (scarcity) & $\begin{array}{l}-1.461^{* *} \\
(0.568)\end{array}$ & $\begin{array}{l}-3.388 * * \\
(1.413)\end{array}$ & $\begin{array}{l}-0.266^{* * *} \\
(0.081)\end{array}$ & $\begin{array}{l}-0.257^{* * *} \\
(0.081)\end{array}$ \\
\hline $\ln (\mathrm{GVIO}) * \ln ($ scarcity) & $\begin{array}{l}0.101^{* *} \\
(0.047)\end{array}$ & $\begin{array}{l}0.269 * * \\
(0.116)\end{array}$ & & \\
\hline $\ln ($ P capital)*ln(scarcity) & $\begin{array}{r}0.002 \\
(0.006)\end{array}$ & $\begin{array}{r}0.006 \\
(0.009)\end{array}$ & $\begin{array}{r}0.002 \\
(0.006)\end{array}$ & $\begin{array}{r}0.006 \\
(0.006)\end{array}$ \\
\hline $\ln$ (wage)*ln(scarcity) & $\begin{array}{l}0.007^{* *} \\
(0.003)\end{array}$ & $\begin{array}{l}-0.024 * * * \\
(0.004)\end{array}$ & $\begin{array}{c}0.007^{* *} \\
(0.003)\end{array}$ & $\begin{array}{r}0.002 \\
(0.003)\end{array}$ \\
\hline $\ln (\mathrm{P}$ materials)* $\ln ($ scarcity) & $\begin{array}{l}0.085^{* * *} \\
(0.009)\end{array}$ & $\begin{array}{l}0.188^{* * *} \\
(0.012)\end{array}$ & $\begin{array}{l}0.084^{* * *} \\
(0.009)\end{array}$ & $\begin{array}{l}0.094^{* * *} \\
(0.009)\end{array}$ \\
\hline $\ln ($ P electricity)* $\ln ($ scarcity) & $\begin{array}{l}-0.043^{* * *} \\
(0.005)\end{array}$ & $\begin{array}{l}-0.079 * * * \\
(0.006)\end{array}$ & $\begin{array}{l}-0.043 * * * \\
(0.005)\end{array}$ & $\begin{array}{l}-0.049 * * * \\
(0.005)\end{array}$ \\
\hline $\ln (\mathrm{P}$ other energy)* $\ln ($ scarcity) & $\begin{array}{l}-0.050 * * * \\
(0.006)\end{array}$ & $\begin{array}{l}-0.091 * * * \\
(0.008)\end{array}$ & $\begin{array}{l}-0.050^{* * *} \\
(0.006)\end{array}$ & $\begin{array}{l}-0.054^{* * *} \\
(0.006)\end{array}$ \\
\hline Average TFP Effect & -0.260 & -0.189 & -0.266 & -0.257 \\
\hline
\end{tabular}

Notes: The dependent variable is the log of total costs. Regressions include enterprise fixed effects, industry*year fixed effects, and factor prices by year. Clustered standard errors are reported in parentheses. We denote significance at the $10 \%(*), 5 \%(* *)$, and $1 \%(* * *)$ levels. Column (2) instruments for scarcity (and its interactions) using cooling degree days and heating degree days (and interactions with factor prices and $\ln (\mathrm{GVIO})$ ). 
Table 5: Industry-Specific Cost Effects of Electricity Reliability

\begin{tabular}{|c|c|c|c|c|c|c|c|c|}
\hline Industry & $\ln$ (scarcity) & $\begin{array}{r}\ln (\text { scarcity }) \times \\
\ln (\text { GVIO }) \\
\end{array}$ & $\begin{array}{r}\ln (\text { scarcity }) \times \\
\ln (\text { P capital }) \\
\end{array}$ & $\begin{array}{r}\ln (\text { scarcity }) \times \\
\ln (\text { wage }) \\
\end{array}$ & $\begin{array}{r}\ln (\text { scarcity }) \times \\
\ln (\text { P materials }) \\
\end{array}$ & $\begin{array}{r}\ln (\text { scarcity }) \times \\
\ln (\text { P electricity })\end{array}$ & $\begin{array}{r}\ln (\text { scarcity }) \times \\
\ln (\mathrm{P} \text { other energy })\end{array}$ & $\begin{array}{r}\text { Average } \\
\text { TFP Effect } \\
\end{array}$ \\
\hline Mining & $\begin{array}{r}-1.629 \\
(1.125)\end{array}$ & $\begin{array}{l}0.209^{* *} \\
(0.093)\end{array}$ & $\begin{array}{l}0.133^{* * *} \\
(0.029)\end{array}$ & $\begin{array}{c}0.045^{*} \\
(0.023)\end{array}$ & $\begin{array}{r}-0.014 \\
(0.034)\end{array}$ & $\begin{array}{l}-0.077 * * * \\
(0.020)\end{array}$ & $\begin{array}{l}-0.088 * * * \\
(0.026)\end{array}$ & 0.812 \\
\hline Food & $\begin{array}{r}1.273 \\
(0.868)\end{array}$ & $\begin{array}{l}-0.148^{* *} \\
(0.069)\end{array}$ & $\begin{array}{r}-0.028 \\
(0.022)\end{array}$ & $\begin{array}{r}0.005 \\
(0.006)\end{array}$ & $\begin{array}{r}0.030 \\
(0.026)\end{array}$ & $\begin{array}{r}-0.001 \\
(0.007)\end{array}$ & $\begin{array}{r}-0.006 \\
(0.010)\end{array}$ & -0.502 \\
\hline Textiles & $\begin{array}{r}-2.666 \\
(3.422)\end{array}$ & $\begin{array}{r}0.194 \\
(0.281)\end{array}$ & $\begin{array}{r}0.013 \\
(0.019)\end{array}$ & $\begin{array}{l}-0.039 * * * \\
(0.012)\end{array}$ & $\begin{array}{l}0.138^{* * *} \\
(0.026)\end{array}$ & $\begin{array}{l}-0.097 * * * \\
(0.012)\end{array}$ & $\begin{array}{r}-0.015 \\
(0.009)\end{array}$ & -0.351 \\
\hline Timber & $\begin{array}{l}-9.863^{* *} \\
(3.837)\end{array}$ & $\begin{array}{l}0.761^{* *} \\
(0.332)\end{array}$ & $\begin{array}{r}-0.032 \\
(0.024)\end{array}$ & $\begin{array}{l}0.061^{* * *} \\
(0.014)\end{array}$ & $\begin{array}{l}0.144^{* * *} \\
(0.034)\end{array}$ & $\begin{array}{l}-0.061 * * * \\
(0.016)\end{array}$ & $\begin{array}{l}-0.111^{* * *} \\
(0.016)\end{array}$ & -1.057 \\
\hline Petroleum & $\begin{array}{l}4.384 * * \\
(2.049)\end{array}$ & $\begin{array}{r}-0.237 \\
(0.159)\end{array}$ & $\begin{array}{r}-0.029 \\
(0.034)\end{array}$ & $\begin{array}{l}-0.037^{* *} \\
(0.016)\end{array}$ & $\begin{array}{l}-0.109 * \\
(0.060)\end{array}$ & $\begin{array}{r}-0.015 \\
(0.010)\end{array}$ & $\begin{array}{l}0.190^{* * *} \\
(0.069)\end{array}$ & 1.442 \\
\hline Chemical & $\begin{array}{r}-2.140 \\
(1.377)\end{array}$ & $\begin{array}{r}0.150 \\
(0.115)\end{array}$ & $\begin{array}{l}-0.020 * \\
(0.012)\end{array}$ & $\begin{array}{r}-0.004 \\
(0.005)\end{array}$ & $\begin{array}{l}0.144 * * * \\
(0.020)\end{array}$ & $\begin{array}{l}-0.046 * * * \\
(0.013)\end{array}$ & $\begin{array}{l}-0.074 * * * \\
(0.014)\end{array}$ & -0.340 \\
\hline Rubber & $\begin{array}{l}-3.963 * * \\
(1.998)\end{array}$ & $\begin{array}{l}0.313^{* *} \\
(0.156)\end{array}$ & $\begin{array}{r}-0.040 \\
(0.035)\end{array}$ & $\begin{array}{r}0.008 \\
(0.018)\end{array}$ & $\begin{array}{r}0.077 \\
(0.049)\end{array}$ & $\begin{array}{r}-0.003 \\
(0.021)\end{array}$ & $\begin{array}{l}-0.042 * \\
(0.025)\end{array}$ & -0.155 \\
\hline Non metal & $\begin{array}{r}-0.128 \\
(0.890)\end{array}$ & $\begin{array}{r}-0.015 \\
(0.081)\end{array}$ & $\begin{array}{l}0.029 * * \\
(0.011)\end{array}$ & $\begin{array}{r}0.001 \\
(0.006)\end{array}$ & $\begin{array}{l}0.064 * * * \\
(0.017)\end{array}$ & $\begin{array}{l}-0.024^{* *} \\
(0.010)\end{array}$ & $\begin{array}{l}-0.070 * * * \\
(0.012)\end{array}$ & -0.293 \\
\hline Metal & $\begin{array}{l}-3.891^{* *} \\
(1.959)\end{array}$ & $\begin{array}{l}0.300^{* *} \\
(0.150)\end{array}$ & $\begin{array}{r}-0.021 \\
(0.022)\end{array}$ & $\begin{array}{l}-0.043^{* * *} \\
(0.009)\end{array}$ & $\begin{array}{l}0.161^{* * *} \\
(0.036)\end{array}$ & $\begin{array}{l}-0.068 * * * \\
(0.020)\end{array}$ & $\begin{array}{r}-0.029 \\
(0.023)\end{array}$ & -0.124 \\
\hline Machinery & $\begin{array}{r}1.799 \\
(2.115)\end{array}$ & $\begin{array}{r}-0.089 \\
(0.162)\end{array}$ & $\begin{array}{r}-0.010 \\
(0.019)\end{array}$ & $\begin{array}{r}-0.001 \\
(0.009)\end{array}$ & $\begin{array}{l}0.053^{* *} \\
(0.024)\end{array}$ & $\begin{array}{l}-0.031 * * * \\
(0.007)\end{array}$ & $\begin{array}{l}-0.011 * \\
(0.006)\end{array}$ & 0.704 \\
\hline Other & $\begin{array}{l}4.351 \text { *** } \\
(1.297)\end{array}$ & $\begin{array}{l}-0.381^{* * *} \\
(0.119)\end{array}$ & $\begin{array}{r}0.005 \\
(0.048)\end{array}$ & $\begin{array}{r}-0.013 \\
(0.024)\end{array}$ & $\begin{array}{r}-0.037 \\
(0.059)\end{array}$ & $\begin{array}{l}0.086^{* *} \\
(0.038)\end{array}$ & $\begin{array}{r}-0.040 \\
(0.049)\end{array}$ & -0.003 \\
\hline
\end{tabular}


Table 6: Aggregate Effects of Electricity Scarcity from 1999 to 2004

Panel A: Effect on Production Costs

$$
\begin{aligned}
& \text { Marginal cost } \\
& \text { (million yuan) }
\end{aligned}
$$

Average Calculation

Factor neutral effects

Factor biased effects

Capital

Labor

Materials

Electricity

Non-electric energy

Overall effects
$-212$

283

$-1.2$

13.7

313

$-56.6$

14.1

70.4

$-10$

274

264
P-value Total effect on

cost, 2000-04

(bill. yuan)

0.00

0.00

$-1,190$

1,580

$-7$

76

1,750

$-317$

79

393

0.23
$\%$ of sample total costs, 2000-2004

\section{Enterprise-level}

Factor neutral effects

$-275$

$-6.72 \%$

Factor biased effects

3,840

3,570

$8.93 \%$

$-0.04 \%$

$0.43 \%$

$9.89 \%$

$-1.79 \%$

$0.44 \%$

$2.22 \%$

Overall effects

Panel B: Effect on Carbon Emissions
P-value Total effect on emissions, \% of sample 1999-2004 total emissions, (th. tons) 1999-2004

\section{Average Calculation}

Total effects

Electric power

\begin{tabular}{|c|c|}
\hline$-4,173$ & $-0.13 \%$ \\
\hline$-3,943$ & $-0.12 \%$ \\
\hline-230 & $-0.01 \%$ \\
\hline
\end{tabular}

Non-electric energy

\section{Enterprise -level}

Total effects

Electric power

Non-electric power

0.91

0.70

0.95

$-230$
$-708$

$-41.3$

$-29$

$-1$

$-27$

Marginal emissions

$-41.3$

7

$-342,000$

$-28,900$

$-339,000$
$-10.70 \%$

$-0.90 \%$

$-10.61 \%$

$-1.55 \%$

$21.69 \%$

$20.17 \%$ 


\section{Scarcity Measure: Thermal Utilization Rate by Grid (1999-2004)}

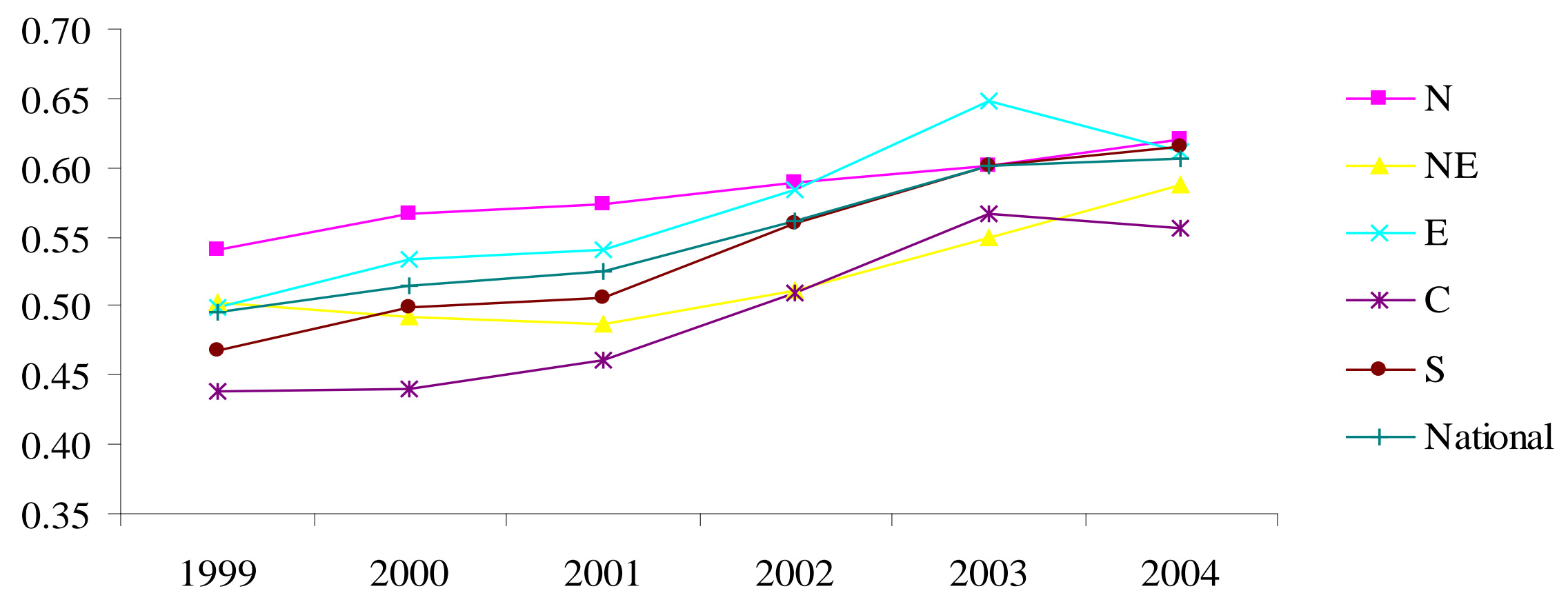

Figure 1: Annual Average Thermal Utilization Rate by Grid, 1999-2004 